\title{
$S_{R} Q_{E}$ LETR AS \\ R $\quad$ V I S T A Apresentação - N. 32 - 2016.2 - Carlinda Nuñez \\ Frans Weiser \\ Maria Cristina Ribas
}

\section{ESTUDOS INTERMIDIAIS E INTERARTES: UM ARQUIPÉLAGO, VÁRIOS ISTMOS, DIFERENTES ITINERÁRIOS}

Este número da Revista SOLETRAS, dedicado à Intermidialidade e aos Estudos Interartes, reúne trabalhos que estudam o discurso poético, em obras nas quais intervêm diferentes linguagens e suportes de comunicação articulados com a palavra escrita. Em outros termos, a literatura, mas não exclusivamente a arte da palavra - finita, na instável e imprecisa formulação de suas propriedades e paradigmas -, é a referência imediata para os materiais aqui analisados; a ela, porém, se sobrepõem novos protocolos de leitura, a incitação cada vez mais forte à combinação com outras artes e a afirmação da produção teórico-literária junto a outras disciplinas. Aqui se encontram, pois, reflexões sobre a produção de textos literários e de outras textualidades que tomam a literatura, direta ou indiretamente, como termo referencial, em função do "comércio das formas" artísticas, estéticas e de materiais epistêmicos que neles se agregam.

Mídias e artes, em pares homogêneos (de mídias diferentes, pertencentes aos estudos propriamente intermidiais, ou de diferentes artes, especificamente ligados aos estudos interartes) ou combinados (mídia e arte), fomentam, de longa data, um campo de criação mais amplo e complexo do que o previsto pelo sistema das artes, em que o múltiplo prevalece sobre o singular; as particularidades disciplinares cedem à inter- e à transdisciplinaridade; os objetos em consórcio presidem relações que só podem se materializar pela eficácia das combinações, sobreposições, transposições. A literatura, nesta zona de confluência, sendo ao mesmo tempo uma arte e uma mídia, se prestou a veicular com eficiência experimentos intermidiais e interartísticos, desde seus primórdios. Quem não reconhece a visualidade dos episódios homéricos, ou os efeitos de uma mímesis musical, nos contos de Hoffmann?

Condizendo com a natureza dialógica e interativa do tema central, inicia-se a leitura por três entrevistas, gentilmente concedidas pelos professores Richard Gordon, da Universidade da Georgia, e Karl-Erik Schollhamer, da PUC-Rio, que nos brindam, cada um com sua particular reflexão, desenhando linhas de força que rasuram e fortalecem o pensamento contemporâneo sobre e na literatura. Contígua a estas, mas já prenunciando o painel multifacetado, o arquipélago de intermidialidades e os istmos interartísticos subsequentes, encontra-se a entrevista - melhor dizendo, intervenção - que devemos ao duo formado pelos professores Roberto Corrêa dos Santos (UERJ) e Miguel Jost (PUC-Rio). 


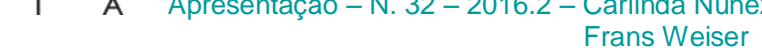

Frans Weiser
Maria Cristina Ribas

Como uma ouverture, o Dossiê é introduzido pelo ensaio intermidial composto em parceria pela voz interventiva Corrêa-Jost, nossos dois últimos entrevistados, que articulam em fractais estética e política, numa revisão da vida social, pelas lentes da mais recente atualidade. O caráter incipit deste texto justifica que ele figure em differAnce, e a seguir os estudos se distribuam em grupos mais ou menos determinados, como se verá.

Avizinham-se, a partir daí, artigos que abrangem tanto questões metadiscursivas - em que a literatura se oferece como objeto de outras artes e instâncias discursivas (o mito, a melodia tradicional, o conto e a sabedoria populares, a fotografia etc.), e estas são objeto do discurso literário -, quanto a análise de obras intermidiais e de diálogos interartísticos. Um expressivo número de pesquisadores (brasileiros, norte-americanos, um australiano e uma colombiana), mais exatamente vinte e sete, ligados a treze universidades e uma secretaria municipal de Educação, assinando artigos produzidos nas três línguas predominantes das Américas - português, espanhol e inglês -, fornece um elenco de modalizações da intermidialidade e dos estudos interartes distribuído em seis grupos com matizes específicas.

Um primeiro grupo de estudos abarca quatro transposições literárias para o cinema, sinalizando o leque de classificações que esta operação transmidiática abre: o conto " $\mathrm{O}$ matador", de Marçal Aquino, ilustra um processo de reescritura fílmica, no filme de Berto Brant que conserva o título da obra-fonte; o romance Sargento Getúlio, de João Ubaldo, é apresentado como adaptação, no filme homônimo de Hermanno Penna; já O Vice-Rei de Uidá, romance de Bruce Chatwin, resulta numa elaborada adaptação, em Cobra Verde, de Werner Herzog. Primus inter pares, o mais casmurro dos protagonistas machadianos inspira a apropriação livre, na tradução audiovisual de Moacyr Góes.

O segundo grupo reúne cinco estudos de extração clássica. Dois deles se dedicam à transplantação de traços estilísticos do épico e do trágico, bem como do páthos heróico e vingativo que lhes são correlatos, na construção dos jogos eletrônicos God of War e The Last of $U s$, respectivamente. Em operação inversa, o terceiro estudo aponta, na correlação entre passagens específicas das Geórgicas, de Virgílio, e no Cynegeticon, de Grattius Faliscus, poetas do séc. I a.C., como o mesmo tema (a lide com animais) resulta em versos muito diferentes: um, de teor bucólico; o outro, um manual técnico - ou seja, uma mesma mídia para receptores/consumidores antípodas. O quarto artigo reinventa o mito de Medeia, enfatizando o caráter estrangeiro (ksénos), e ao mesmo tempo estranho, da exilada trácia, numa ópera pósmoderna, evocativa de uma melodia medieval, mas executada em estilo lírico e orquestrada 
por músicos trajados como robôs. No quinto artigo, Robert Lepage "hamletiza" seu experimento performático, discutindo o ser ou não ser de sua apropriação multimidiática de Hamlet.

As articulações entre literatura e artes plásticas são focalizadas numa dupla de artigos: um celebra a versatilidade da palavra, constatável nas narrativas orais e na materialidade que ela adquire nas artes plásticas e visuais; o outro correlaciona a famosa tela de Vélázquez, Las Meninas, e o poema "O Corvo", de Edgar Allan Poe, objetos artísticos que, associados, provocam a expansão do campo percepcional de ambas as obras; a aventura convoca discursos filosóficos a contracenar na reflexão, que abala as próprias noções de ensaio e de crítica de arte em que este torvelinho teórico-artístico acontece.

As duas adaptações criativas de Medeia e Hamlet se enquadrariam igualmente num grupo de adaptações intermidiais a serviço de uma tradução cultural do velho mito e da tradicional fábula dinamarquesa, juntamente com o estudo sobre as duas Alices de Lewis Carroll, traduzidas espe(ta)cularmente para o português e o millieu brasileiros dos anos 2000. $\mathrm{O}$ artigo sobre a prima donna refugiada poderia fazer par com o artigo sobre o papel da mídia como fator de potenciação da obra musical de Chico Buarque e de Caetano Veloso, num grupo de estudos sobre literatura e música. Questão de preferência, a formação de grupos segundo as especificidades.

Last but not least, o último grupo de estudos põe em correlação mídias visuais (fotografia e TV) e história cultural. Aqui encontram-se três artigos centrados na discrepância entre a Cinderela dos contos de fada e suas pósteras dos reality shows norte-americanos, em filmes angolanos que elaboram uma revisão da identidade cultural do país, em função de um passado pós-colonial e resistente mapa das vicissitudes herdadas a partir de esfacelamentos em série; e finalmente de uma fotografia que captura vivências no Rio de Janeiro atual à maneira de um tableau vivant: palco de memórias, fantasmas e medium de reflexão.

Em seu conjunto, os conteúdos deste número da SOLETRAS propõem uma abordagem teórico-crítica da narratividade através das mídias, sejam elas antigas ou contemporâneas, eruditas ou vernaculares, por intermédio de combinações, transposições, citações ou referências. As especificidades de cada intermidialização ou operação interartística, como se poderá perceber no espaço tempo da leitura, são modalizadas conforme a equação proposta.

Esperamos que deste volume saiam novos artigos, aquarelas que se misturem à fluidez do cristal líquido, que alimentem a potência significativa da linguagem e, quem sabe, o tema - 
Apresentação - N. 32 - 2016.2 - Carlinda Nuñez

este compósito heteróclito que ora lhes trazemos às mãos e aos olhos - continue a dinamizar e a expandir os campos literário, interartístico e intermidial como processos encadeados, ação em gerúndio, iluminação mútua.

Boa leitura, bons estudos, boas viagens entre meios, livros e obras. De arte.

Carlinda Nuñez

Frans Weiser

Maria Cristina Ribas 